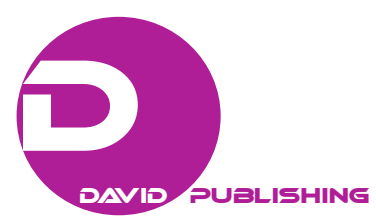

\title{
The Instability of the Economy Pre-financial Crisis-Some Considerations on the Phillips Curve: It's Still Reliable
}

\author{
Giovanni Antonio Cossiga \\ Università degli Studi “La Sapienza”, Roma, Italy
}

\begin{abstract}
The paper tests the hypothesis that the traditional Phillips curve will have a new relevance today, though with very different purposes from those who have inspired research in the past. Therefore, we investigated the hypothesis that the traditional trade-off between inflation and unemployment can be ascertained during the period of abnormal real estate boom and whether there are differences in its manifestation. With the analytical method and econometric was ascertained the validity of the trade-off between inflation and unemployment in the period of serious instability of economic systems, in large part with both rising variables. Trade-off is absent in relatively stable economies. The Phillips relation is not an event that renews itself in all economic systems, regardless of time and space. On the contrary, it is a temporary phenomenon, which occurs when the economy is struggling with the upward trend in inflation. It should therefore be listed as a manifestation of the unstable state in which a system is subjected due to shock. In this context, the relationship Phillips can manifest itself in an independent manner, without there being a recognizable direction, so it can be a sort of signal that the engine of the economy is jamming. According to this view, therefore, the Phillips relationship could be reborn to new life, regaining value as a phenomenon generated by instability and therefore recognized as a marker that leaves its mark, when an economy is suffering.
\end{abstract}

Keywords: inflation, unemployment, irrationality, temporary phenomenon

\section{Introduction}

The curve of William Phillips, an economist born in New Zealand, went through 50 years of science despite the large change in the landscape of the global economy, for a singular adaptation of the initial model in the context of a global development also tumultuous. The original idea that ties in a relationship heterodox inflation and unemployment, has been accepted by the community of economists when, in 1960, Paul Samuelson and Robert Solow integrated the "Phillips Curve" into the Neo-Keynesian building. We are in the fifties and early sixties, when inflation was generally low and the economy was relatively stable.

A condition almost extraordinary, in the light of subsequent experience, which looked like the ideal milieu to acquire, through the trade-off Phillips, a valuable tool to control unemployment. In fact, during the sixties tensions occur within the labor market, following the economic slowdown after a long period of strong growth.

Giovanni Antonio Cossiga, doctor, Presidente del Collegio dei sindaci del Policlinico Umberto I, Università degli Studi "La Sapienza", Roma, Italy.

Correspondence concerning this article should be addressed to Giovanni Antonio Cossiga, Via Fernando Colombo 1200154 Roma, Italy. 
The ability to have a tool to control unemployment seemed to offer great opportunities. ${ }^{1}$ Nevertheless, back in the seventies the Phillips curve seems inadequate to explain the problems posed by stagflation, with unemployment and inflation moving in the same direction. These problems on the validity of the curve were partially resolved with the new approach proposed by Friedman (2007). ${ }^{2}$

There is to say that the consistency of the statistical relationship between inflation and unemployment does not drag with it, in terms of logical coherence and practical feasibility, the possibility to check events in terms of unemployment. The lack of feasibility of the maneuver on the rate of inflation for the benefit of employment is indisputable. Especially in our time with the world economy grappling with the aftermath of a severe financial crisis and Europe struggling with an overwhelming sovereign debt. Whatever it is, this situation has raised many concerns and raises the same conjecture that it is possible to interfere with wisdom and prudence on the phenomenon of inflation.

Consider, in terms of intervention on inflation, which remains enigmatic the possibility of sterilizing inflation to the desired level, to maintain the lowest unemployment. In an economy with inflation also relatively low (>10\%), empirical evidence confirms that there appears a natural tendency of the inflation movement to growth, in virtue of an autonomous process of acceleration. The balance of the operation, therefore, remains uncertain, because the costs to control inflation lead to frustrating the expected promotional effect on the unemployment rate.

This limit also does not affect the significance of the relationship between the price system and level of unemployment, rather discredits the hypothesis that it could handle the inflation profile with the precision of a watchmaker, to support the economy. It is also to consider that the conditions of inflation, generally low in the last decade, can awaken similarities with the situation of the fifties, then reviving the improbable options arising from the trade-off between inflation and unemployment.

In the following pages, we examine the theory and hypotheses that, scientifically, were made by well-known economists about a trade-off between inflation and unemployment. Let us now delineate the context of research, checking if there is an upper or lower limit for the validity of the Phillips curve and controlling the behavior of the trade-off during the two-thousand years. We continue in the next chapter to see if there is, and when, a relationship between the two variables, inflation and unemployment (economy proxy). For confirmation of the assumptions, we proceed with the use of econometrics. Finally, we draw some conclusions based on the results obtained.

\section{Theory and Hypothesis}

\footnotetext{
1 The work presented by Phillips in 1958, is eminently empirical. Just two years after its publication, two papers appeared, one of the theoretical content (Lipsey, 1960) and the other on the conduct of macroeconomic policies (Samuelson \& Solow, 1960). The debate on the "Phillips curve", which also resulted in an impressive number of contributions, took over the moves by these two interpretations from the original work of Phillips. After almost 50 years it is possible to say that "since the publication of the original article by Phillips, the report was modified in many ways. Despite all this activity, many issues remain unresolved because a lot of work done since the rate of Phillips was based on a misunderstanding of the original report" (Desai, 1975, p. 2).

2 The Phillips Curve showed a trade-off between unemployment and inflation. However, the problem that emerged with it in the 1970s was its total inability to explain unemployment and inflation going up together-stagflation. According to the Phillips Curve they weren't supposed to do that, but throughout the 1970s they did. Friedman then put his mind to whether the Phillips Curve could be adapted to show why stagflation was occurring, and the explanation he came up with, was to include the role of expectations in the Phillips Curve-hence the name "expectations-augmented" Phillips Curve. Friedman argued that there were a series of different Phillips Curves for each level of expected inflation. If people expected inflation to occur then they would anticipate and expect a correspondingly higher wage rise. Friedman was therefore assuming no "money illusion"-people would anticipate inflation and account for it.
} 
To say the truth, the situation of the world economy today is light-years distant from the post-war. Consider that in the recent past, the concerns of the major monetary authorities, the Federal Reserve and European Central Bank, focused on the possible prevalence of deflation, seen as negative inflation. A drift towards deflation that the Fed has decided to hold through the adoption of extraordinary measures, such as the Quantitative Easing $(\mathrm{QE})$, to keep down the long-term interests, to increase the availability of money for credit and, last but not least, to keep the dollar weak.

It is not difficult to draw a parallel with the fifties-sixties. At the time, after the acceleration in the postwar period, the economy gave the first signs of overheating with inflation, while was growing the concern of a exhaustion of the cycle. With the prospect of being able to act on employment, using the Phillips trade-offs, governments enticed and attracted economists in the wake of Samuelson and Solow's interpretations. In the current situation, the creeping deflation in America and in Europe raises the risk that advanced economies are infected with the Japanese syndrome, with the prospect of a long period of weak or stalled growth. In this perspective, in which economists such as Kenneth Rogoff did not hesitate to ask for a rise in inflation, the therapies according to the Phillips curve seem light-years distant.

Not only is the tendency to deflation undermining the efficiency of the Phillips curve; in addition, with the acceleration of inflation, already in the late sixties and during the seventies, the relationship between inflation and unemployment did not seem to work anymore.

"Unfortunately for this hypothesis, additional evidence failed to conform with it. Empirical estimates of the Phillips curve relation were unsatisfactory. More important, the inflation rate that appeared to be consistent with a specified level of unemployment did not remain fixed: in the circumstances of the post-World War II period, when governments everywhere were seeking to promote "full employment", it tended in any one country to rise over time and to vary sharply among countries. Looked at the other way, rates of inflation that had earlier been associated with low levels of unemployment were experienced along with high levels of unemployment. The phenomenon of simultaneous high inflation and high unemployment increasingly forced itself on public and professional notice, receiving the unlovely label of "stagflation". (Friedman, 2007)

It is certainly suggestive that the plasticity of the Phillips curve with the changing economic landscape, is reconfigured as the relationship between unemployment and accelerating inflation. Following the rise in inflation expectations, so it would be possible to keep the unemployment rate in parallel ${ }^{3}$. According to this hypothesis, every economic system has been identified a natural rate of unemployment or NAIRU (Non-Accelerating Inflationary Unemployment Rate), which identifies a balance between inflation expectations and natural rate of unemployment.

Then on the theme of change in slope of the Phillips curve, from negative during the fifties and sixties and seventies too positive, Friedman (1976) observes:

Just as the natural-rate hypothesis explains a negatively sloped Phillips curve over short periods as a temporary

\footnotetext{
3 A more radical revision was required. It took the form of stressing the importance of differences between actual and anticipated magnitudes. It restored the primacy of the distinction between real and nominal magnitudes. There is a natural rate of unemployment at any time determined by real factors. This natural rate will tend to be attained when expectations are on the average realized. The same real situation is consistent with any absolute level of prices or of price change, on the real cost of holding money balances. In this respect, money is neutral. On the other hand, unanticipated changes in aggregate nominal demand and in inflation will cause systematic errors of perception on the part of employers and employees, similar to what will initially lead unemployment to deviate in the opposite direction from its natural rate. In this respect, money is not neutral. However, such deviations are transitory, though it may take a long chronological time before they are reversed and finally eliminated, as anticipations adjust.
} 
phenomenon that will disappear as economic agents adjust their expectations to reality, so a positively sloped Phillips curve over somewhat longer periods may occur as a transitional phenomenon that will disappear as economic agents adjust not only their expectations but their institutional and political arrangements to a new reality. When this is achieved, I believe that as the natural-rate hypothesis suggests the rate of unemployment will be largely independent of the average rate of inflation, though the efficiency of utilization of resources may not be. High inflation need not mean either abnormally high or abnormally low unemployment.

Individually, even in the event of rising inflation, as in the seventies, the correlation between high inflation and high unemployment seems to maintain a downward slope in both the short- and long-term, in partial deviations from the theory of long-term vertical curve, encouraged by Friedman (1968) and Phelps (1968). At this regard, one must consider that inflation shows to have an ability to follow an autonomous inertial acceleration process, i.e., independent from the causes that gave the rise. Variability leads to sharing comments on Friedman's possible independence of the two phenomena, when there are recurrent conditions of high inflation. Therefore, in these conditions, we can consider a random correspondence as statistical.

On the question of the validity and limits of viability of the trade-off between the two variables, it is interesting to read the thoughts of Robert E. Lucas on the subject. In the essay "Nobel Lecture: Monetary Neutrality", Lucas, with graphics in the notes (Stockman, 1998), "provides six plots of annual inflation rates against unemployment rates for various sub periods of the years 1960-94, for the United States. Panel f plots of Phillips curve (Phillips, 1958) for the entire period, in this panel, the two variables appear to be completely unrelated. On the other hand, the five panels for sub-periods (or at least for the sub-periods since 1960) seem to show a clear, negative relation." 4
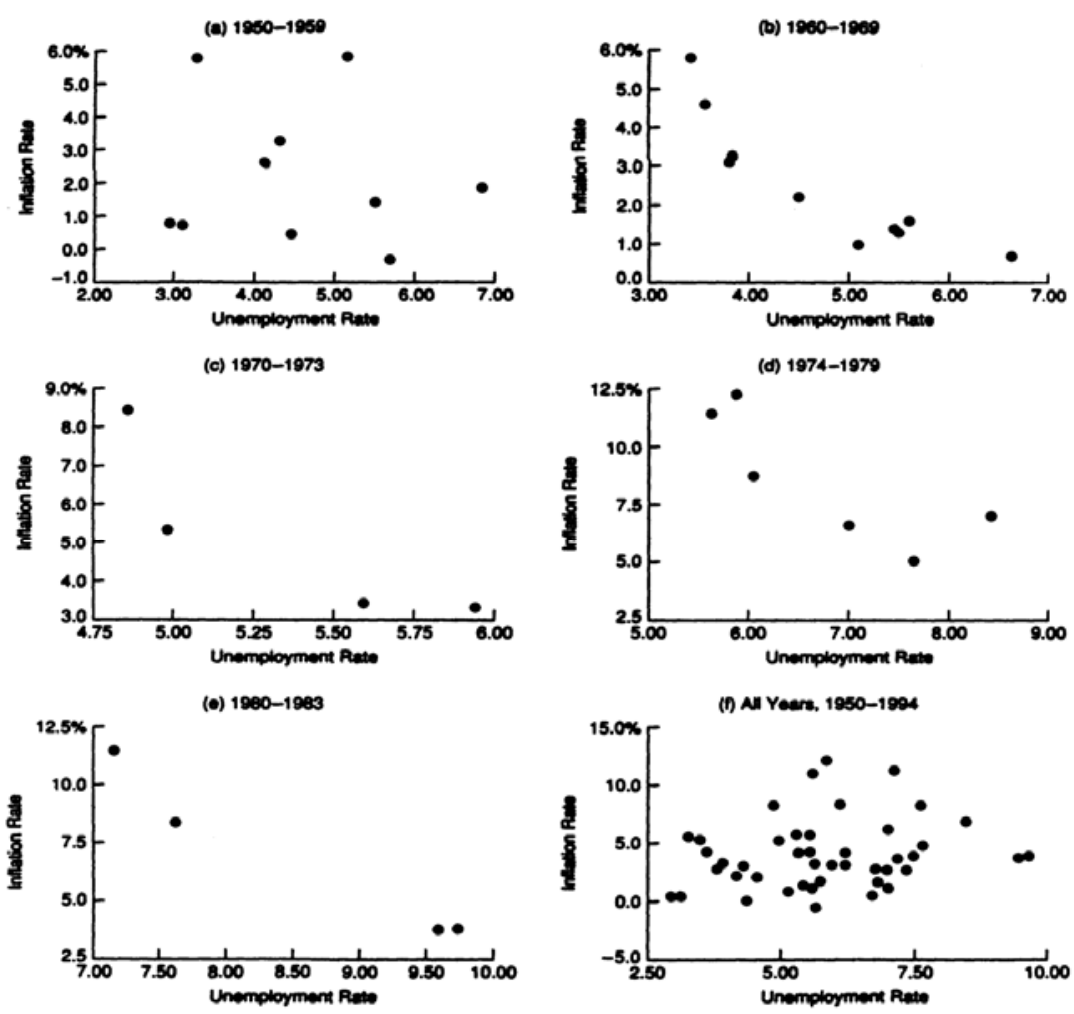

FIG. 3.-Inflation and unemployment in the United States 


\section{Research Design}

\section{Limits on the Validity of Phillips Curve in Case of Low or Very High Inflation}

Based on these premises, we examined the hypothesis that there may be limits on the validity of Phillips curve, limits that would exclude in principle the existence of a trade-off and, consequently, the ability to enable meaningful options for employment support.

The limits to the existence of the Phillips curve would be found specifically:

- For the most stable economies (inflation $\leq 2 \%$ );

- For very inflated economic systems.

We can argue - in theory - that at this extreme limits, as we succinctly stated, cannot continue to manifest a measurable relationship between the two variables, inflation, and unemployment rate. The trade-off would then be fading both at the stage of high inflation as in the opposite case, a quasi-stable economy. In these situations, then there could be no trade-offs in both the short- and long-term.

In the case of medium and high inflation and stagflation — which was the condition of the major economies during the seventies - the original formula of Phillips no longer worked because of the coincidence of high inflation and high unemployment. The initial formulation integrated with inflation expectations seemed to adapt better to the conditions of an economy subject to high inflation. In an inflated economy, inflation and unemployment are not linked by a negative correlation, rather than by a positive correlation (increase for both inflation and unemployment). ${ }^{5}$

However, with inflation of around $20 \%$ and more, the economy continues to show reduced recovery potential, followed by recession, which is reflected in employment levels. In this specific condition, inflation - if not controlled - follows a trend in inertial acceleration, moving up and left the Phillips curve. In other words, the driver determining the rate of unemployment, and even more in the case of inflation acceleration, is essentially the economic cycle, which becomes less efficient on the side of growth when the rate of inflation is increasing. With the fall on efficiency of the economy, it is possible to argue that they dissipated the relationship between unemployment and inflation, as they move now unrelated.

On the theme of business cycle developments in relation to the rate of inflation, it must be recalled the work of Bruno and Easterly (1995). With a large survey, the authors argue that the economy is screwed into a prolonged recession, when prices reach and exceed the speed of $30 \%-40 \%$ per year. Beyond that threshold, therefore, the main variables are all subject to ongoing correction in the economic system, so now we cannot assume a significant link of the type described by the Phillips curve.

In a context of high inflation $(\leq 40 \%-50 \%)$, in which the expectations are for a gradual rise in nominal prices, the relationship between inflation and unemployment gradually becomes a progressive formal nullification of the trade-off. The inflation acceleration, partly unexpected, now follows a trajectory that has become devoid of links with other variables, then consistent with the negative development of

\footnotetext{
5 The model containing expectations in a simple formulation consists of three relations: the expectations-augmented Phillips curve $\Delta w=f(U)+\alpha p^{\varepsilon}$;

a relationship expressing the price increases as the difference between the growth of the wage rate and the increase in productivity $\Delta \mathrm{p}=\Delta w-\Delta \pi$

an equation explaining the formation of expectations through the mechanism of adaptation : $\Delta \mathrm{p}^{\varepsilon}=v\left(\mathrm{p}-\mathrm{p}^{\varepsilon}\right)$.

By these three equations we get the final relation: $\Delta p=g(U)+\alpha p^{\varepsilon}$; according to which, inflation is driven by excess demand for labor as in the case of the simple Phillips curve, besides the inflationary expectations.
} 
the economy. ${ }^{6}$

At these latitudes of high inflation ( $40 \%$ and above), loses its meaning the same usability of a fine-tuning maneuvering that has targeted the maneuvering of the relationship between inflation and unemployment. In any case, it seems unlikely that the high level of inflation in the economy can stabilize and even allow achieving the minimal goal of a natural rate of unemployment consistent with the adverse conditions.

Once admitted the existence of an upper limit on the inflation level to the validity of the trade-off, it is envisaged for the hypothesis that there is also a lower limit to the validity of the trade-off. A lower limit, then, which also leads to the evanescence of the relationship between inflation and unemployment. A limitation that could coincide with the ideal conditions of an economy. An economy is relatively stable, then, with a constant inflation rate, less than $2 \%$, where the minimum unemployment tends to coincide with its natural rate and on a development path straight with a slope depending from the potential.

Fast-growing economies in the industrialized countries during the fifties and in Southeast Asia during the next decade, such as Singapore and Taiwan, awarded stability by accelerating development. In times that are more recent, you can include Korea, as an example of compatible growth in a balanced and almost stable economy.

Well, let say stable economy: the phenomenon of unemployment at the minimum and tensions on the labor market does not occur. The trade-off between employment and inflation should not occur, given a very low inflation $(<2 \%$ ) generally constant (unlike the high variability of inflation) and unemployment coinciding with the natural rate of unemployment. An ideal situation was defined by the Phillips curve in the long run, such as vertical without any trade-off.

According to this approach, the throughput of the Phillips curve would be confined to two extremes, marked by an upper limit, in the case of high inflation, and a lower limit, marked by low inflation and stable economy. In the first case, the level of instability is such to exclude the possibility that it could endure an inverse relationship between inflation and unemployment, although you may experience random coincidence statistics. In the case of established stability, it is excluded any option chance of the mix between inflation and unemployment, for the obvious reason that the status is already optimal.

All this will have some appreciable consequences, because this approach would limit the possibility of a short-term trade-off only to economies suffering from inflation, between a minimum of $5 \%-10 \%$ to a maximum

\footnotetext{
${ }^{6}$ In the following graphic, taken from "Inflation Crises and Long-run Growth" by Michael Bruno and William Easterly, it summarized the comments, covering 127 countries for the period 1960-92, about the behavior of economic growth in relation to annual inflation rates, increasing from stability to rates higher than $1000 \%$. The survey highlights that the degradation of economic growth in response to inflation increase is limited, if the nominal prices trend lies within a $20 \%$ annual increase. The economy instead enters recession if inflation exceeds $30 \%-40 \%$, with a product loss by $2 \%$ when the annual prices rate exceeds $100 \%$; loss rising to $4 \%$ and $6 \%$ if the annual inflation exceeds the $200 \%$ and $1000 \%$ accordingly.
}

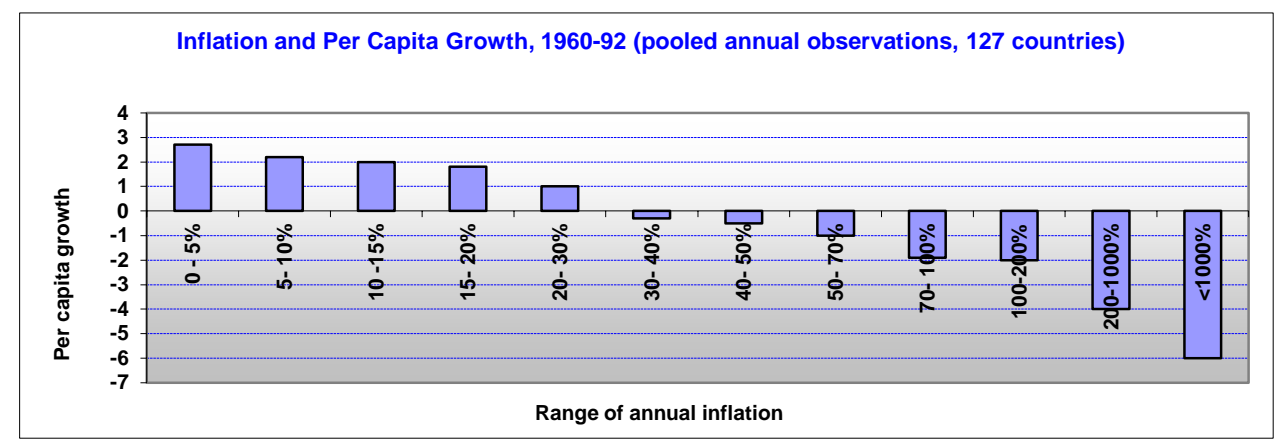


of $40 \%$ (maybe less). In other words, an area of an intervention for the options offered by the trade-off of great interest, not just theoretical, it is potentially occurred along the sixties and seventies, when most of the industrialized countries were subject to inflation and growth, impetuous and only after a decade slowed down.

A situation is now distant in time, after more than a decade of disinflation that has in fact cooled the interest shown towards the operational potential of the trade-off. During the last decade, the major countries in Europe and North America are showing a low inflation fluctuating around the $2 \%$ or minus, in China and India the average inflation is about double and, finally, Japan is in deflation.

The present world economic context, therefore, generally excludes the presence of an appreciable short-run trade-off, at least in major continental areas. This would exclude the possibility that inflation could influence the labor supply, while is back in vogue the primary relationship between economic growth and unemployment rate.

We can add, however, that low inflation does not coincide with economic stability. In particular, in the last decade, Europe, North America, and Austral area were hit by a severe financial crisis, after experiencing a prolonged speculative bubble in real estate. The world economy has experienced a long period of instability, during which there has been a creeping tendency to deflation, a trend that has served as a shock absorber of inflationary pressures from international prices of oil, raw materials, and foodstuffs. A very difficult environment, making unlikely as well as highly improvident, the possibility of manipulating the inflation rate, but for purposes other than those postulated by Phillips with the aim of containing sovereign debt.

\section{The Phillips Trade-off During the Years Two-Thousand}

Set aside any aspirations about the profitability of the policy trade-offs, it seems useful to check if the economic landscape of this decade has had a statistically significant inverse relationship between unemployment and inflation. It is also useful to verify if along the decade, and particularly in the period between 2003 and 2008, during which the speculative bubble occurred in real estate, there was statistical evidence of a trade-off between the inflation rate and the unemployment level, in the original version of Phillips.

In the long period of formation of the speculative bubble, the speculative excitement in real estate has moved slightly to the other sectors of the economy, so the number of countries involved in the bubble growth has been modest. Similarly, during the period under review, the rate of inflation has remained almost neutral with regard to speculative emphasis. The strong excitation of speculative international prices of oil and raw materials has had thus a weak echo on prices.

Strangely, the overall picture provided by countries struggling with the speculative bubble, principally the United States and the Western Europe, was characterized by a relatively weak economic growth and low inflation. A picture could appear affirming and, at least in part, justifying its lack of concern and fair attention to the risk. At least until the economic system has come close to the explosion of the bubble, the worsening conditions of risk finally become evident. During the formation of a speculative bubble, then, the condition of the economy is difficult to be interpreted because ambiguous, to look stable, although the economy in good health is not subject to speculative impulses.

Given the characteristics of weak growth and low inflation of the bubble-prone areas, we can suppose that, in countries that have experienced strong pressure from speculation, and it is appreciable that the presence of the relationship is postulated by Phillips. We may observe, in other words, a non-marginal gain on employment, 
in parallel with a modest decrease on the inflation rate. Otherwise, it would be possible to establish a Phillips effect, with obvious trade-off in the short term, in countries that, during the examined period, have maintained the economy during the last decade within terms of relative stability.

The supposed absence of a Phillips curve in economies with a consolidated stability in the period under review appears sustainable for several reasons. First, the stable conditions to maximize growth potential levels. Therefore, it is not desirable, and perhaps even impossible, any maneuver to push over the development level. Second, the price system is stable and low price fluctuation is frictional. In absence of significant external shocks, monetary policy maintains a neutral attitude regarding the fate of the prices movement, so a maneuver is not feasible to define an acceptable policy mix between inflation and unemployment. Only in the case of a derailment from the stable state, the decline in potential growth and employment could revive the option about the mix between unemployment and inflation levels.

In other words, the option offered by the Phillips trade-off is in any case an anomaly in terms of social and political fair ethics, as well as of proper economy administration. This option is aiming to bridge the gap emerging in the growth and level of unemployment, towards their potentials. The aim is not, therefore, to cure the system disease producing a decrease in efficiency, but to try getting around it, through the inflation operation, although there is always a great chance to leave the field open to "unfair tax". The possibility of recourse to the trade-off for the potential support of growth and employment can configure the operation of political filibustering, just to remedy abuses in the economic and fiscal system that led to instability.

According to this view, all interventions aiming to promote the maneuver of the inflation rate would be unorthodox and essentially ineffective. This objection does not mean that we should completely forget the potentialities, which can be offered by determining the existence of the relation observed by Phillips. In fact, if we can prove that the short-run Phillips curve is a specific abnormality inside unstable economies - an anomaly not occurring inside of stable economies - the trade-off analysis could be called more simply as a statistical tool for the research of instability state in the economy.

The problem of having a thermometer to measure the instability of a system, has assumed a specific value for the ambiguous behavior of the main variables (low growth and low inflation) in continental areas where, during the last decade, has been formed the bubble which after all exploded. Some mixed signals have diverted the attention of authorities and public opinion from the real state of the economy, which was subject to a profound instability but appeared as falsely healthy.

\section{Research Method}

\section{The Search for a Balanced Relationship Between Inflation and Unemployment}

We want to seek confirmation of the thesis that the Phillips trade-off may happen in practice in the globalized economies of the third millennium and to infer statistically the relationship between inflation rate and the unemployment level. We note here that, according to the outlined views, the mutual trend of the two variables would not be a natural consequence of development, as an inevitable attribute-taking place without limits or barriers. In contrast, the equilibrium relationship established between the two variables seems rather to identify an anomaly of systems that have deviated from the natural tendency and are in a state of instability, where inflation is the most visible symptom.

Thus, the Phillips relationship has no reason to occur in countries where over the time a stable condition

was developed. Not only and not so much because there is no reason to act on inflation (low) to promote the 
employment rate, which already is at its maximum. In a stable economy, growth is moving in a straight line and with an inclination that is commensurate with the potential. Therefore, it occurs a complete absence of trade-off between prices, generally stable, and unemployment level.

The behavior of the two variables - inflation, unemployment - is largely dependent on the state of the economy. Firstly, we will proceed to compare the trends in the inflation and unemployment rate in countries that, during the last decade, have suffered most from the real estate bubble, then experiencing a deep financial crisis. The same procedure will then be extended to countries that, always over the past 10 years, have presented smooth public finances, low inflation, and lack of attraction towards the speculation chimera.

We will proceed meanwhile, to show the graphs of the trends for the two variables under consideration inside the first and second group. This brief overview is useful for a visual approach to the behavior of inflation and unemployment in the two different groups of countries, followed by the search for an equilibrium relationship, always between the two variables. We propose to determine whether and under what conditions there is a cointegration relationship between inflation and unemployment trends, which indicates the possible existence of a trade-off Phillips, at least for a group of countries identified below.

Here below we reproduce (Figure 1) the trend of inflation rate and unemployment level in the U.S., France, Sweden, and Spain. These are countries, which have experienced the effects of both the speculative boom and the financial crisis, due to the instability of their economies. For Italy, the economy instability is the result of the enormous public debt. The "Belpaese" (Beautiful country) remained less sensitive to real estate speculation, but was particularly hit by the recession and financial crisis.

In the series of Graphs, n.1 appears clear enough a link between inflation and unemployment for the period under review. For USA, U.K., France, and Sweden, the decline in unemployment from the period 2003 to 2007 moves in concert with the increase in average inflation. For the U.S. quarterly average inflation rose from 0.64 in the period $1994-2000$ to $0.78 \%$ in the period $2001-2007$, from 0.44 to $0.51 \%$ in England, from 0.34 to 0.53 in France and from 0.35 to 0.44 in Sweden. The strong surge of unemployment in the period 2008-2010 is concomitant with the inflation decline at the starting of a creeping deflation on prices.

Figure 2 shows the trends for the inflation rate and the unemployment level in Germany, Korea, and New Zealand. These countries have partially avoided the stronger effects of the speculative boom, due to the relative stability in the economy.

In countries with stable economy, and particularly in Korea and New Zealand, during a period marked by the boom in the real world in many areas, employment remains stable individually, with clear independence from inflation (quarterly). Even in Germany, the profile of unemployment is certainly independent from the inflation rate.

\section{Co-integration and ADF Test on the Variables Inflation and Unemployment}

The visual image of the phenomenon is eloquent enough to discern the different behavior of the two variables, depending on the stable or unstable economy condition. For statistical confirmation that the Phillips relationship is still relevant, at least for economies which left the stable state, we need to determine whether and under what conditions is realized a balance relationship between the two variables, inflation and unemployment. In other words, it must be checked whether the series of two variables, generically identified as $y_{t}$ and $x_{t}$, are both outfitted with a stochastic trend and, once given this feature, if they are subject to a co-integration relationship. 

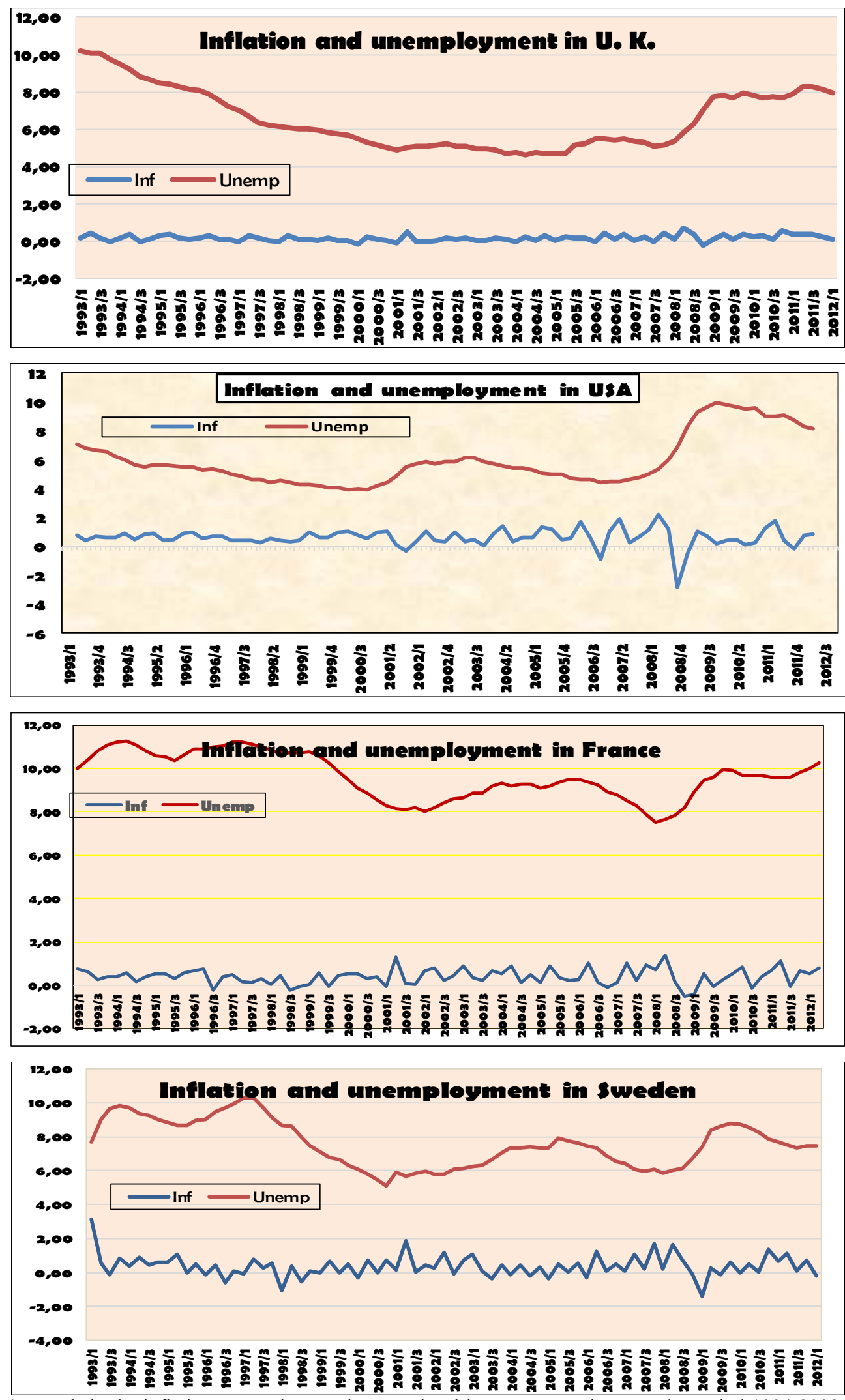

Figure 1. Trends in the inflation rate and unemployment level in some countries over the period 1994-2008. Source: Elaboration on data from OECD-Statistics. 

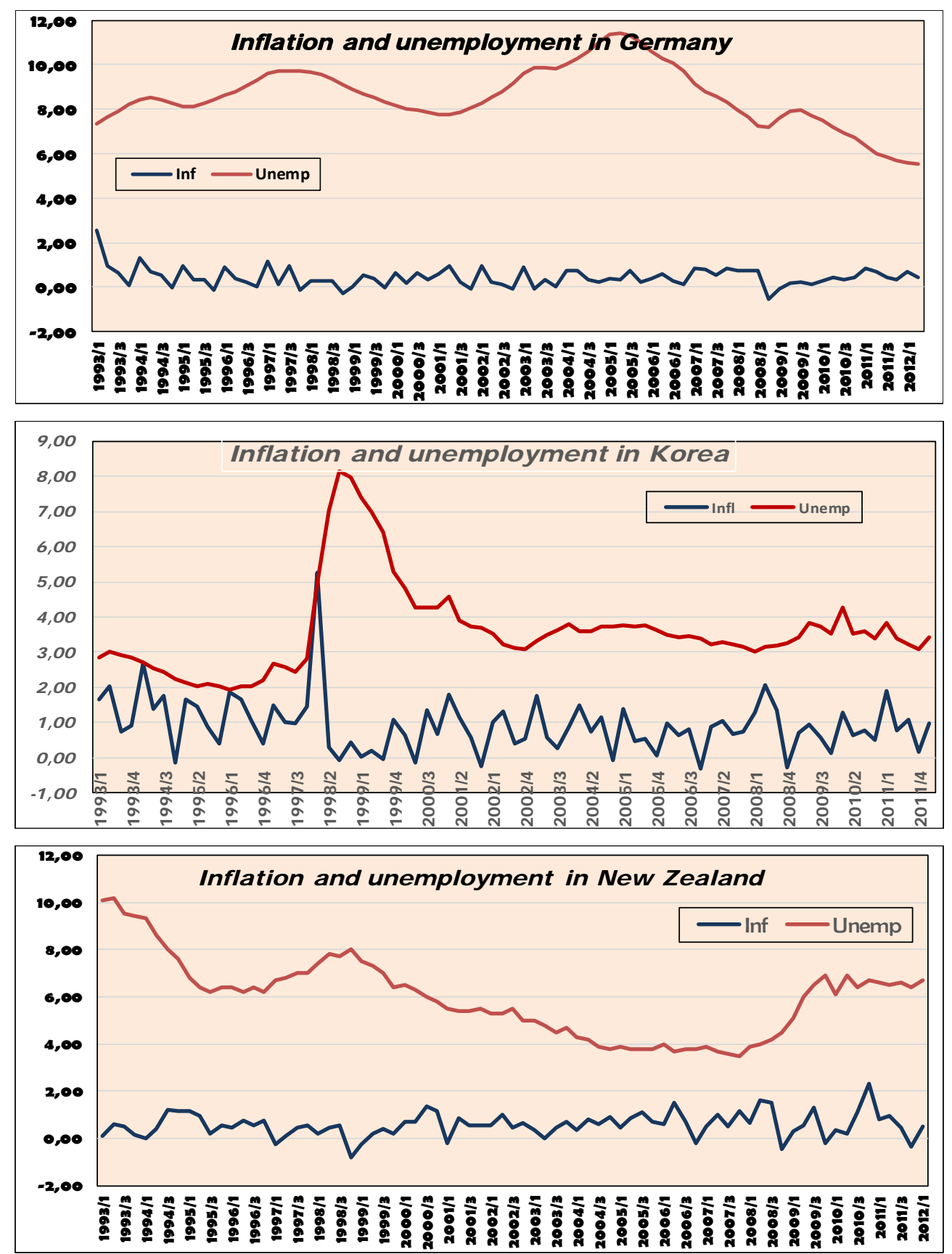

Figure 2. Trends in the inflation rate and unemployment level in some countries over the period 1994-2008. Source: Elaboration on data from OECD-Statistics.

In other words, given the equation:

$$
y_{t}=\beta \mathrm{x}_{\mathrm{t}}+\mathrm{z}_{\mathrm{t}}
$$

set the condition:

$$
\begin{gathered}
\mathrm{y}_{\mathrm{t}} \sim I(1) \text { and } \mathrm{x}_{\mathrm{t}} \sim I(1) \\
\mathrm{y}_{\mathrm{t}}-\beta \mathrm{x}_{\mathrm{t}}=\mathrm{z}_{\mathrm{t}} \text { where } \mathrm{z}_{\mathrm{t}} \sim I(0)
\end{gathered}
$$

It can be argued that between $\mathrm{y}_{\mathrm{t}}$ and $\mathrm{x}_{\mathrm{t}}$ there is a cointegration relationship. 
Therefore, there is a priority when, for the period under review, inflation and unemployment series are integrated with order $I(1)$. Then it must combine with the co-integration tests, to see whether a linear combination of the two variables is stationary, even though each of them is not. Whereas the two variables are linked by a co-integration relationship, there is an equilibrium relationship between the two variables.

For research about the integration degree of the two series under consideration, the following general equations are submitted to the ADF test (Augmented Dichey Fulkler Test):

$$
\begin{gathered}
\Delta \operatorname{Inf}_{\mathrm{t}}=\alpha+\beta \mathrm{t}+\rho * \operatorname{Inf}_{\mathrm{t}-1}+\rho_{1} \Delta \operatorname{Inf}_{\mathrm{t}-1}+\rho_{2} \Delta \operatorname{Inf}_{\mathrm{t}-2}+\ldots+\rho_{\mathrm{k}} \Delta \operatorname{Inf}_{\mathrm{t}-\mathrm{k}}+\varepsilon_{\mathrm{t}} \\
-\Delta \text { Unemp }_{\mathrm{t}}=\alpha+\beta \mathrm{t}+\rho * \operatorname{Unemp}_{\mathrm{t}-1}+\rho_{1} \Delta \text { Unemp }_{\mathrm{t}-1}+\rho_{2} \Delta \text { Unemp }_{\mathrm{t}-2}+\ldots+\rho_{\mathrm{k}} \Delta \text { Unemp }_{\mathrm{t}-\mathrm{k}}+\varepsilon_{\mathrm{t}}
\end{gathered}
$$

for the presence of an autoregressive root unit testing the hypothesis that $\mathrm{H}_{0}: \delta=0$ against the unilateral alternative $\mathrm{H}_{1}: \delta<0$.

The survey was extended to numerous countries of Western Europe, Asia, and Oceania, using the full expression (4), including the trend " $t$ " (number of observations) in the case that the series "Inf.", in the alternate hypothesis, is stationary around a deterministic trend. To choose the number of delays has been used the Bayes Information Criterion (BIC), indicating an optimal value of 4.

By using the ADF test, we have found the integration degree for the two-series relating to inflation and unemployment. Since under the null hypothesis of a unit root, the ADF statistic does not have a normal distribution, we proceeded to compare the test results for each variable with the special critical values of the ADF statistic for the null hypothesis. We assumed that for countries listed below in the period between 1991 and 2011 the inflation trend (quarterly) was stationary around a deterministic trend for: Sweden, Norway, and Korea. For lack of requirements on the stochastic trend when related to the variable "inflation", we have excluded these countries from the second stage of the investigation using the co-integration tests.

Moving within some of the economies of the countries for which it is confirmed the stochastic trend, we reported in Table 1 - just for the variable "inflation"- the values of the ADF test on quarterly data, compared with critical values of statistics ADF for the null hypothesis. The reporting periods are between 1991 and 2011, as specified in the table for each country. Table 2 is reporting instead the values of the test on quarterly data regarding the variable "unemployment".

Table 1

The Values of the ADF Test on Quarterly Data for the Variable "Inflation"

\begin{tabular}{lllll}
\hline Countries & $\begin{array}{l}\text { Result of the ADF test under the null } \\
\text { hypothesis of unit root (inflation trend) }\end{array}$ & $\begin{array}{l}\text { Critical values of ADF } \\
\text { test at the 5\% }\end{array}$ & $\begin{array}{l}\text { Statistic } \\
\text { F values }\end{array}$ & Reporting periods \\
\hline USA & -2.589 & -2.86 & 8.442 & $1991 / 2-2011 / 1$ \\
France * & -2.961 & $-3.43 *$ & 14.495 & $1992 / 2-2011 / 1$ \\
U.K. & -2.343 & -2.86 & 29.673 & $1991 / 2-2011 / 1$ \\
Italy & -2.805 & - & 8.487 & $1992 / 2-2011 / 1$ \\
Germany & -2.449 & - & 15.325 & $1991 / 2-2011 / 1$ \\
Irlanda & -2.570 & - & 8.607 & $1991 / 2-2011 / 1$ \\
Portugal & -2.231 & - & 35.025 & $1992 / 2-2011 / 1$ \\
Spain & -2.860 & - & 77.926 & $1991 / 2-2011 / 1$ \\
Finland & -2.374 & - & 10.625 & $1991 / 2-2011 / 1$ \\
Netherlands & -2.515 & - & 31.095 & $1991 / 2-2011 / 1$ \\
Denmark & -3.124 & $-3.43 * *$ & 56.390 & $1991 / 2-2011 / 1$ \\
Belgium * & -3.893 & $-3.96 * * *$ & 9.864 & $1994 / 1-2011 / 1$ \\
\hline
\end{tabular}


Table 1 continued

\begin{tabular}{lllll}
\hline Countries & $\begin{array}{l}\text { Result of the ADF test under the null } \\
\text { hypothesis of unit root (inflation trend) }\end{array}$ & $\begin{array}{l}\text { Critical values of ADF } \\
\text { test at the 5\% }\end{array}$ & $\begin{array}{l}\text { Statistic } \\
\text { F values }\end{array}$ & Reporting periods \\
\hline Mexico & 2.636 & -2.86 & 5.102 & $1991 / 2-2011 / 1$ \\
Chile & -2.409 & - & 14.673 & $1991 / 2-2011 / 1$ \\
Japan & -3.383 & - & 46.537 & $1991 / 2-2011 / 1$ \\
Australia $*$ & -3.897 & $-3.96 * * *$ & 10.075 & $1991 / 2-2011 / 1$ \\
OECD Total & -2.358 & -2.86 & 13.146 & $1991 / 2-2011 / 1$ \\
G7 & -3.960 & $-3.96 * * *$ & 17.680 & $1991 / 2-2011 / 1$ \\
\hline
\end{tabular}

Notes. * Elaboration on quarterly data from OECD-Statistics; * Hypothesis of series with intercept and time trend; ** Hypothesis of series with intercept and time trend. Critical values of ADF test at the 5\%; *** Hypothesis of series with intercept and time trend. Critical values of ADF test at the $1 \%$.

Table 2

The Values of the ADF Test on Quarterly Data for the Variable "Unemployment"

\begin{tabular}{|c|c|c|c|c|}
\hline Countries & $\begin{array}{l}\text { Result of the ADF test under the null } \\
\text { hypothesis of unit root trend } \\
\text { (unemployment) }\end{array}$ & $\begin{array}{l}\text { Critical values of ADF test } \\
\text { at the } 5 \%\end{array}$ & $\begin{array}{l}\text { Statistic } \\
\text { F values }\end{array}$ & Reporting periods \\
\hline USA & -1.925 & -2.86 & 11.016 & $1991 / 2-2011 / 1$ \\
\hline France & -2.016 & - & 17.661 & $1992 / 2-2011 / 1$ \\
\hline U.K. & -0.057 & - & 3.263 & $1991 / 2-2011 / 1$ \\
\hline Italy & -1.458 & - & 4.751 & $1991 / 2-2011 / 1$ \\
\hline Germany & -0.559 & - & 15.344 & $1991 / 2-2011 / 1$ \\
\hline Irlanda & -0.067 & - & 8.607 & $1991 / 2-2011 / 1$ \\
\hline Portugal & -0.728 & - & 3.627 & $1992 / 2-2011 / 1$ \\
\hline Spain & -0.760 & - & 13.807 & $1991 / 2-2011 / 1$ \\
\hline Finland & -1.444 & - & 19.799 & $1991 / 2-2011 / 1$ \\
\hline Netherlands* & -3.837 & $-3.96 * *$ & 37.705 & $1991 / 2-2011 / 1$ \\
\hline Denmark & -2.367 & -2.86 & 3.077 & $1991 / 2-2011 / 1$ \\
\hline Belgium & -2.256 & - & 2.1515 & $1994 / 1-2011 / 1$ \\
\hline Mexico & -0.515 & - & 1.209 & $1991 / 2-2011 / 1$ \\
\hline Chile & -2.053 & - & 2.162 & $1991 / 2-2011 / 1$ \\
\hline Japan & -1.893 & - & 2.025 & $1991 / 2-2011 / 1$ \\
\hline Australia & -1.754 & - & 2.805 & $1991 / 2-2011 / 1$ \\
\hline OECD total & -1.351 & - & 12.266 & $1992 / 2-2012 / 1$ \\
\hline G7 & -1.570 & - & 9.170 & $1992 / 2-2012 / 1$ \\
\hline
\end{tabular}

Hypothesis of series with intercept and time trend. Critical values of ADF test at the $1 \%$.

We can now proceed towards the co-integration tests, which are the same tests for the existence of a unit root applied to the regression residuals (1), i.e.:

$$
\mathrm{y}_{\mathrm{t}}-\beta_{1} \mathrm{x}_{\mathrm{t}}=\mathrm{z}_{\mathrm{t}} \quad \text { that is } \quad \operatorname{Inf}_{\mathrm{t}}-\beta_{1} \text { unemp }_{\mathrm{t}}=\mathrm{z}_{\mathrm{t}}
$$

where the expression $\mathrm{z}_{\mathrm{t}}$ represents the regression residuals (1). Therefore, the EG-ADF test is still the $t$-test in the regression:

$$
\Delta z_{\mathrm{t}}=\rho * \mathrm{z}_{\mathrm{t}-1}+\rho_{1} \Delta \mathrm{z}_{\mathrm{t}-1}+\rho_{2} \Delta \mathrm{z}_{\mathrm{t}-2}+\ldots+\rho_{\mathrm{k}} \Delta \mathrm{z}_{\mathrm{t}-\mathrm{k}}+\varepsilon_{\mathrm{t}}
$$

The existence of a co-integration relationship between variables "Inflation" and "Unemployment" is confirmed if and when the following relationship is satisfied: 


$$
\operatorname{Inf}_{\mathrm{t}}-\beta_{1} \text { unemp }_{\mathrm{t}}=\mathrm{Z}_{\mathrm{t}} \quad \text { if } \quad \mathrm{z}_{\mathrm{t}} \sim I(0)
$$

In other words, we must check if the EG-ADF test on regression residuals (1) does receive, at a significance level of $5 \%$, the hypothesis of a unit root, otherwise an alternative is prevailing that the linear combination (4) is stationary. If the presence of a unit root is confirmed even in the regression residuals equation (1), we must conclude that there is no equilibrium relationship between the two variables, inflation, and unemployment. All this would draw to exclude the existence of the Phillips relationship, at least in the period in question, inside any economy showing these results.

Conversely, if the EG-ADF test results in favor of the alternative, and therefore the linear combination (4) is stationary, we have a statistical confirmation that the two variables are linked by a co-integration relationship. In this case, it would be verified from a statistical point of view that the economy in question, for the period considered, is realizing a Phillips relationship between the two variables, inflation rate and unemployment level.

\section{Some Results on the Validity of Phillips Relationship in the Next Decade}

Based on these indications, we have drawn up the detailed tables below. Table 3 includes the short list of economies seeming to be immune from the Phillips relationship, given that the EG-ADF test confirms the presence of a unit root in the regression (4). In a few words, no one of the countries investigated confirms the validity of Phillips relationship in a period between 2000 and 2008, when within many continental areas is starting a devastating speculative bubble spreading worldwide.

This singular configuration may be partly enlightened regarding the curious relation occurring throughout the time of the bubble expansion, between inflation trend and GNP. Nevertheless, when the economy is slowly restarting on the upheaval of the bubble acceleration, the inflation trend appears to contract trying to answer to real move of economy towards the bubble, disrupting in financial crisis, deflation, and profound recession. That configuration, synthesized as an almost normal condition (steady inflation and slow economic growth), may be interpreted by EG-ADR test as a feeble economic state, not as a bad involution of a devastated economy.

Nevertheless, some alarm bells may arise from a not superficial lecture of Table 3, where we can clearly read a strong difference when comparing the Australia test value that is very slight, with the corresponding value for Portugal that is so close to critical test value. We may do a similar consideration about the values calculated for some countries, such as USA, UK, Italy, and Norway, all very close to critical value. In every case, the results enlighten an economic malaise situation, though the extreme ambiguity of the environment induced by the bubble is scarcely interpreted throughout the EG-ADR test.

However, we could obtain more appropriate values from the test if we would discern and deduct from the GDP growth profile an almost virtual part provoked by the bubble effervescence; that portion which would be cancelled by the strength of financial crisis. This investigation purpose could be not so difficult and may be reached regarding those countries that have experienced in the past the hard reality of speculative bubble and the asperity of financial crisis. We can further consider that for the cleansing of GDP virtual part developed by the bubble, we may use also the information nonetheless contained in inflation profile during that anomalous period. In fact, the inflation rate is insensitive to the bubble rush and we may use it as a sort of trustworthy mirror inside the economic ambient. The correction of GDP trend will be made in a measure, proportional to decline in the inflation rate. 
Table 3

The EG-ADF Test on Regression Residuals (4), Whenas It Is Not Confirmed the Existence of the Phillips Relationship

\begin{tabular}{lllll}
\hline $\begin{array}{l}\text { Countries not linked by a } \\
\text { co-integration relationship }\end{array}$ & $\begin{array}{l}\text { ADF test results for } \\
\text { checking the null hypothesis } \\
\text { of unit root }\end{array}$ & $\begin{array}{l}\text { Critical values of EG-ADF } \\
\text { test at the 5\% }\end{array}$ & $\begin{array}{l}\text { Statistic } \\
\text { F values }\end{array}$ & Reporting periods \\
\hline Australia & -0.789 & 3.41 & 0.238 & $1991 / 2-2004 / 3$ \\
Japan & -1.502 & - & 2.539 & $1991 / 2-2004 / 3$ \\
Germany & -1.354 & - & 0.586 & $1991 / 2-2004 / 3$ \\
Chile & -2.023 & - & 1.959 & $1991 / 2-2004 / 3$ \\
Mexico & -1.306 & - & 2.564 & $1991 / 2-2004 / 3$ \\
France & -1.421 & - & 0.763 & $1992 / 2-2004 / 3$ \\
Denmark & -1.315 & - & 0.489 & $1991 / 2-2004 / 3$ \\
Netherlands & -2.256 & - & 1.928 & $1991 / 2-2004 / 3$ \\
Finland & -1.749 & - & 1.781 & $1991 / 2-2004 / 3$ \\
Ireland & -1.799 & - & 1.048 & $1991 / 2-2004 / 3$ \\
Portugal & -2.049 & - & 2.287 & $1991 / 2-2004 / 3$ \\
Italy & -1.578 & - & 0.737 & $1991 / 2-2004 / 3$ \\
Spain & -1.749 & - & 2.054 & $1991 / 2-2004 / 3$ \\
U.K. & -1.797 & - & 2.516 & $1991 / 2-2004 / 3$ \\
USA & -1.714 & - & 2.108 & $1991 / 2-2004 / 3$ \\
& & - & & 1.660 \\
OECD total & -1.863 & - & 1.591 & $1991 / 2-2004 / 3$ \\
G 7 & -1.717 & - & &
\end{tabular}

It is certainly a singular outcome that most of the economies appear on the ambiguous ground of almost-stability, while the extremely crisis is anyhow incumbent. This singularity is a real threatening, because that false appearance of economic health might hide a sleepy condescendence and a substantial indifference —or even an unforgivable approval-during the expanding phase of the bubble. Moreover, this is exactly what happened during the bubble formation in the period 2005-2007. After this brief remark on the subtle menace due to the lowered capability of understanding the threat loudness in this anomalous situation, we can observe the different test response, by shifting only a few quarters ahead the period under observation.

In Tables 3 and 4, we may verify the difference that is appearing, as already exposed, only six-nine quarters after, all along the period 2001-2009. Table 3 includes the economies of those countries which continue not being influenced by the Phillips relationship, given that the EG-ADF test does confirm the presence of a unit root in the regression (4) and refuses the alternative of a stationary trend. On the other hand, Table 4 lists the important countries and areas that appear instead being influenced by Phillips relationship, as the EG-ADF test results now favorable to the alternative and therefore the linear combination (4) is stationary. We have, therefore, a statistical confirmation that the two variables are linked by a co-integration relationship. In this case, it would be verified from a statistical point of view that the economies in question, for the period considered, are subjected to a Phillips relationship between the two variables: inflation rate and unemployment level.

It could seem quite strange for the rapid shift of countries like USA, U.K., Italy, and important areas like OECD (total) and Group of G7, from a condition of low sensibility to another demonstrating instead a close relation of inflation rate and unemployment trend. However, consider that in the period of increasing financial crisis (during late 2008 and 2009), the two variables inflation and unemployment are moving in opposite 
directions. While the nominal prices go down under the deflationist pressure, the unemployment is tending to instead to rise for the devastating effects of economic depression. In other words, the declining profile of inflation rate in the years under review, confirms a relationship, although the unemployment data are rapidly declining in opposition to classic Phillips relationship.

Table 4

The EG-ADF Test on Regression Residuals (4) That Still Excludes the Existence of the Phillips Relationship

\begin{tabular}{lllll}
\hline $\begin{array}{l}\text { Countries not linked by a } \\
\text { co-integration relationship }\end{array}$ & $\begin{array}{l}\text { ADF test results for } \\
\text { checking the null hypothesis } \\
\text { of unit root }\end{array}$ & $\begin{array}{l}\text { Critical values of EG-ADF } \\
\text { test at 5\% }\end{array}$ & $\begin{array}{l}\text { Statistic } \\
\text { F values }\end{array}$ & Reporting periods \\
\hline Germany & -1.870 & -3.41 & 1.189 & $1991 / 2-2009 / 4$ \\
Netherlands & 1.594 & - & 1.203 & $1991 / 2-2009 / 4$ \\
Finland & -2.289 & - & 1.757 & $1991 / 2-2009 / 4$ \\
Australia & 2.226 & - & 1.469 & $1991 / 2-2009 / 4$ \\
\hline
\end{tabular}

Table 5

The EG-ADF Test on Regression Residuals (4) in the Case Is Confirmed the Existence of the Phillips Relationship

\begin{tabular}{lllll}
\hline $\begin{array}{l}\text { Countries linked by a } \\
\text { co-integration relationship }\end{array}$ & $\begin{array}{l}\text { ADF test results for } \\
\text { checking the null hypothesis } \\
\text { of unit root }\end{array}$ & $\begin{array}{l}\text { Critical values of EG-ADF } \\
\text { test at 5\% }\end{array}$ & $\begin{array}{l}\text { Statistic } \\
\text { F values }\end{array}$ & Reporting periods \\
\hline Japan & -9.093 & -3.41 & 32.805 & $1991 / 2-2009 / 4$ \\
U.K. & -10.842 & - & 56.680 & $1991 / 2-2009 / 4$ \\
USA & -5.014 & - & 9.907 & $1991 / 2-2009 / 4$ \\
Chile & -5.148 & - & 9.335 & $1991 / 2-2009 / 4$ \\
Spain & 7.391 & - & 18.433 & $1991 / 2-2009 / 4$ \\
Denmark & 6.066 & - & 9.415 & $1991 / 2-2009 / 4$ \\
Ireland & 10.775 & - & 30.490 & $1991 / 2-2009 / 4$ \\
Belgium & 5.586 & - & 9.2834 & $1991 / 2-2009 / 4$ \\
Italy & -5.530 & - & 8.322 & $1992 / 2-2009 / 4$ \\
Portugal & 4.378 & - & 5.299 & $1992 / 2-2009 / 4$ \\
France & -7.616 & - & 15.996 & $1992 / 2-2009 / 4$ \\
& & - & & $1991 / 2-2009 / 3$ \\
OECD total & -7.253 & - & 25.305 & $1991 / 2-2009 / 3$ \\
G 7 & -11.44 & - & & \\
\hline
\end{tabular}

Source: Elaboration on data from OECD-Statistics.

Nonetheless, the wavering reality regarding the actual Phillips relationship, at least for many countries and areas, may still be surprising. As you can see in Table 6, if we continue investigating the behavior of the two variables inflation and unemployment, forwarding time for about six-eight quarters, we will assist to another unexpected change.

All the countries indicated in Table 5 as linked by a co-integration relationship, have moved in the following period 2010-2012 again in a neutrality position between the inflation and unemployment trends, just confirming the extraordinary character of Phillips relationship.

In short, the close linkage between the variables at issue seems to be manifested actually only in exceptional circumstances, like deep economic recession, creeping deflation, serious financial crisis. In any case, the rapid transition from the close relationship between the two variables to the situation of peaceful neutrality only some 
years after, is certainly due to the change in the unemployment rate occurred during the period 2010-2012. The brusque loss of jobs during the deep recession stops from 2010 in all countries and areas at issue by an uncommon usage of Keynesian maneuvers, a more accommodating monetary policy, and an abnormal liquidity growth to avoid a devastating deflation. The reversal of the unemployment rate that after experiencing a rapid growth gradually recovers has occurred while the inflation rate is continuing its creeping movement. Therefore, it breaks the potential statistical relation that just a few quarters before had connected the brusque unemployment surge with the concomitant low inflation.

Finally, Japan deserves a separate mention. The economy of the "Land of the rising sun" has not, indeed, the typical requirements of stability. The growth is low and below its potential, inflation is low and tending to deflation, the public debt is among the highest within OECD countries. This is the typical picture of a country with unstable economy, which for over a decade does not find the road to recovery, despite the assistance of a macroscopic public sector intervention and a monetary policy more than accommodating. A result is anomalous, but confirming the thesis that in an economy struggling with deflation, the relation expressed by Phillips does not appear compatible.

Table 6

\begin{tabular}{lllll}
\hline $\begin{array}{l}\text { Countries not linked by a } \\
\text { co-integration relationship }\end{array}$ & $\begin{array}{l}\text { ADF test results for } \\
\text { checking the null hypothesis } \\
\text { of unit root }\end{array}$ & $\begin{array}{l}\text { Critical values of EG-ADF } \\
\text { test at 5\% }\end{array}$ & $\begin{array}{l}\text { Statistic } \\
\text { F values }\end{array}$ & Reporting periods \\
\hline Japan & -0.671 & -3.41 & 1.775 & $1991 / 2-2011 / 1$ \\
U.K. & -0.166 & - & 0.709 & $1991 / 2-2011 / 1$ \\
USA & -1.199 & - & 1.038 & $1991 / 2-2011 / 1$ \\
Chile & -0.767 & - & 2.556 & $1991 / 2-2011 / 1$ \\
Spain & 0.331 & - & 0.955 & $1991 / 2-2011 / 1$ \\
Denmark & 0.908 & - & 0.251 & $1991 / 2-2011 / 1$ \\
Ireland & 0.963 & - & 0.483 & $1991 / 2-2011 / 1$ \\
Belgium & 0.072 & - & 0.068 & $1991 / 2-2011 / 1$ \\
Italy & 1.588 & - & 2.597 & $1992 / 2-2011 / 1$ \\
Portugal & -0.912 & - & 0.448 & $1992 / 2-2011 / 1$ \\
France & 1.136 & - & 0.524 & $1992 / 2-2011 / 1$ \\
OECD total & -0.547 & - & 0.449 & $1991 / 2-2011 / 1$ \\
G 7 & -0.255 & - & 0.466 & $1991 / 2-2011 / 1$ \\
\hline
\end{tabular}

Source: Elaboration on data from OECD-Statistics.

\section{Attempt of Interpretation}

The result reached is not trivial. It is telling us that the Phillips relationship is not generally an event occurring in all economic systems, with unlimited time and space. However, it is a transitory phenomenon occurring when an economy is struggling with rising inflation trend. Recently, a close relationship between the two variables at issue has clearly emerged during the biannual period 2008-2009 in many countries and areas affected by a severe depression, while the financial crisis was running worldwide. Therefore, we may classify as a manifestation of the unstable state of a system hit by a shock.

Going back to the relationship linking the prices movement towards the unemployment level, it would seem enough that the unstable condition of the economy is manifested through a rising or declining inflation trend, even moderate as we have experienced recently in occasion of serious financial crisis by the decade end. Inside an 
environment with inflation, the Phillips relationship is created without any recognizable direction, i.e. independently, so that it could be interpreted as a clear sign that the economy engine is jamming. According to this view, the Phillips relationship could be born again to a new life, as a phenomenon generated by instability and therefore, recognized as a strong marker leaving its imprint, whenever an economic system is suffering.

To confirm this unusual nature, and in any case transitional, of the Phillips relationship, there is a neutrality clear evidence of the relationship between inflation and unemployment levels in an economic system that for a long time maintained a state near to stability. This would be enough to allow us to say that in a stable economy (depending on lowest inflation and growth potential) there is no reason to use the alchemy of inflation fine-tuning. Indeed, in a stable environment it would be impossible to stimulate employment through inflation, because of the absence of any link between the calm price trends and relatively stable level of employment.

No less significant is also the behavior of the two variables, when there is a persistent tendency to deflation, as in the case of Japan. Even under those circumstances undoubtedly revealing a serious instability, the maneuver of the inflation rate is not feasible to mitigate the negative trend. A success of such a maneuver would allow Japan to go out finally from the sad reality of deflation, with probable influence on growth and employment. On this topic, recently, Krugman (the Nobel Prize), has proposed some innovative options to push the Japanese economy out of deflation block ${ }^{7}$. In a consistent way, the statistical evidence does not confirm, in the case of Japan, the existence of a correlation between the inflation rate and the unemployment level.

This raises the question about the probable reasons for the alternate behavior of the Phillips relationship. Being understood that the trade-off is questionable and also weak in a stable economy, one could wonder whether there is a reason justifying the presence of a relationship between "Inflation" and "Unemployment" inside an economy struggling with a persistent inflation, and therefore unstable.

Therefore, it seems reasonable to assume that in absence of a director controlling the phenomenon, the presence of a Phillips relationship in all economies struggling with the inflation phenomenon (slow growth and rising unemployment) should make us reflect on the potential need for that intimate relationship. This potential need could relate to the natural tendency towards economic stability. In fact, with the abandonment of stability, typical and recurring phenomena would occur, like the inflation itself as well as various peculiar links established between the main variables.

This brief premise allows some additional thoughts on the ways to interpret the phenomenon. Meanwhile, we should consider that, because the bonds of Phillips relationship again emerge, conjuncture and employment must take a converging trend, where employment is rising during the recovery phase and is declining during the recession. Likewise, inflation should move in conjunction with the cycle, i.e., rising during the recovery and

\footnotetext{
7 Paul Krugman - in Japan'S Trap: “It may seem strange to return to monetary policy as an option. After all, haven't we just seen that it is ineffective? This point needs enlarging upon. Because the traditional IS-LM framework is a static one, it cannot make any distinction between temporary and permanent policy changes. And partly as a result, it seems to indicate that a liquidity trap is something that can last indefinitely. But the framework here, rudimentary as it is, suggests a quite different view. In the flexible-price version of the model, even when money and bonds turn out to be perfect substitutes in period 1, money is still neutral - that is, an equiproportional increase in the money supply in all periods will still raise prices in the same proportion. So what would a permanent increase in the money supply do in the case where prices are predetermined in period 1 ? Even if the economy is in a liquidity trap in the sense that the nominal interest rate is stuck at zero, the monetary expansion would raise the expected future price level $P^{*}$, and hence reduce the real interest rate. A permanent as opposed to temporary monetary expansion would, in other words, be effective- because it would cause expectations of inflation. Let us now bring this discussion back to earth, and to Japan in particular. Of course, the Bank of Japan does not announce whether its changes in the monetary base are permanent or temporary. But we may argue that private actors view its actions as temporary, because they believe that the central bank is committed to price stability as a long-run goal. And that is why monetary policy is ineffective".
} 
declining during the negative phase. In other words, inflation, economy, and employment should move in a concerted manner by following the cyclical pattern of the economy, which we can consider the driver of the other two variables. Thus, inflation and employment will have to move in parallel on the rise during the recovery phase, whereas, when the cycle is reversed, the two variables should move in gradual decline and again in parallel. As we saw in the previous section, the two variables, although correlated, move in opposition when the economy tends to deflation.

We know that economies from a long time almost stable proceed on the development path following a line with a slope depending on the respective potentials. In this equilibrium state, the concerted relationship between inflation, economic cycle, and employment could not exist.

In fact, the regularity of the variables movement (constant inflation rate, linear growth of economics, and employment) exclude the possibility of moving with the sinuous movement of the cycle, the economy with an inflation tied to economic cycle, as well as to employment trend. ${ }^{8}$

\section{Conclusion}

The classic cyclical economic situation in countries subject to inflation would be the scenario where it could be embodied a more or less intimate relation among the three variables: economy, inflation, and employment. This strong relationship, surely influenced by the economic cycle, would also bring out the Phillips curve, as revised in the light of the Keynesian theory. During the recovery phase, the economy growth is dragged along with inflation and high employment, while the cycle negative phase and the economy slowdown are transmitted to inflation and employment levels. During the entire cycle of the economy, therefore, we may observe the tradeoff between inflation and unemployment.

Differently, in a natural (stable) economic condition the growth becomes linear, not sinuous, while we do not observe any change in the almost-constant inflation profile: as proved by recent experiences regarding countries, which since nineties have avoided the troubles of excessive indebtedness and the consequent speculative bubble.

Therefore, the uniformity and harmony of a relatively stable economy and, by contrast, the rhythmic diversity of an unstable economy, provide two different scenarios able to explain the reasons for the Phillips relationship transitory nature. Defined as a feature of an unstable system, it would seem unwise for the use of trade-offs as an economic policy instrument, thus neglecting the clear signs of instability sent by the economic system. It would be a new error, which emphasizes the error that led to the instability of the system, i.e., a different and unnatural use of the relationship between inflation and unemployment, which we can consider as part of a strategy of economic system for the stability recovery.

In other words, we may assume that economic systems possess an autonomous capacity for their survival, even though the development process may undergo significant shocks. This "resistance gift" we can interpret it is the result of systems natural tendency towards the stability. Therefore, the attraction to the natural condition of stability is realized in a path of growth, which is following the market forces, in absence of any shock. Then, when an economic system has become unstable because of a shock, the natural tension to stability should skip to an independent correction process, which may gradually help a return to normal operability. The fact that the

\footnotetext{
${ }^{8}$ For example, note the following Figure 3 on inflation and GNP in Norway, a country cited as a relatively stable during the observation period. From the Figure we can note that since the nineties, inflation is around $2 \%$ while the GNP has followed the same time with a linear trend in growth, until the financial crisis of 2009.
} 
Phillips relationship emerges when the economy is derailed from the natural stability, may suggest that this complex relationship may be part of the natural defense mechanism, to correct a persistent instability.

To confirm the thesis that the economic cycle may have an important role in the project core goal of maintaining stability, there is the awareness that phenomena related to the Phillips curve are replicated without any change in time, whenever systems derail from the normal condition of stability. At this point, you could claim the thesis of the economist J. Schumpeter, to whom we owe a detailed analysis of economic cycles. ${ }^{9}$

Here, we are interested in some aspects of the Austrian economist thought. In his first work, The essence and core content of theoretical economics (1908), he sustained the affinity of the economy to the natural sciences. In other words, the world of physics with its natural laws seems to invade the economy world, which receives some natural impulses to correct the course of derailing economic systems.

The theoretical model of J. Schumpeter is aiming to interpret the "creative destruction" as a critical function of the renewal process, based on innovation. The creative destruction is glimpsed as a correction model making the system free from the waste, so making possible the revival of the stability growth path. More generally, following the Austrian economist thought, we can interpret the economy "recession" as a process of creative destruction, expensive but necessary to gradually eliminate errors and alterations that made the system unstable. ${ }^{10}$ The decisional and promotional role of Innovation is the powerful and natural added value of a tool, able to overcome the instability due to human errors.

Over the time, in a stable system the main instrument of economic growth, i.e., innovation, can be reasonably acting in an integrated cooperation accompanying the economic growth process. Therefore, we can argue that there would not be an abrupt cessation destroying the obsolete equipment and suddenly promoting physical and organizational innovation to launch a new model, but a more gradual and cooperative process of smooth replacement of obsolete technologies.

\footnotetext{
${ }^{9}$ From Capitalism, Socialism, and Democracy (1942), by Joseph Schumpeter: "The opening up of new markets, foreign or domestic, and the organizational development from the craft shop to such concerns as U.S. Steel illustrate the same process of industrial mutation - if I may use that biological term - that incessantly revolutionizes the economic structure from within, incessantly destroying the old one, incessantly creating a new one. This process of Creative Destruction is the essential fact about capitalism". (p. 83)
}

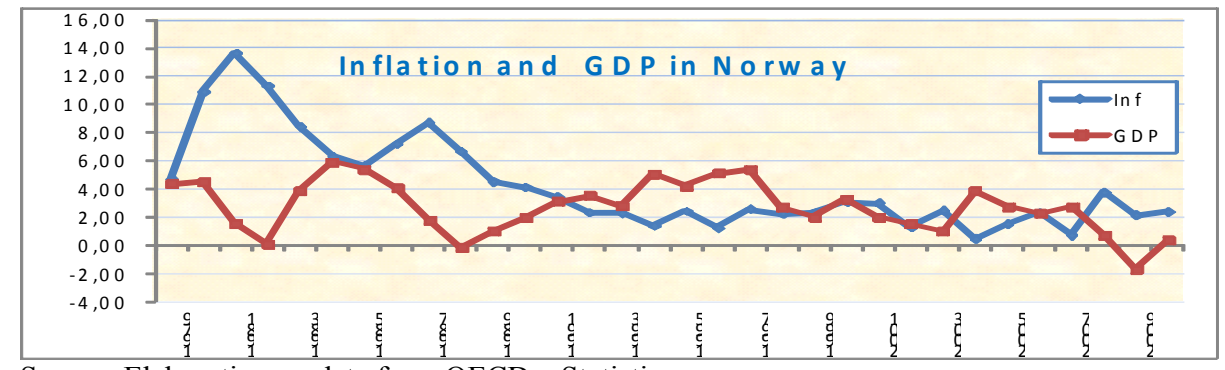

Source: Elaboration on data from OECD—Statistics

${ }^{10}$ With the succession of economic cycles, recessions may become more frequent and deeper in parallel with the profile of an increasing inflation. This process, left to act with just limited interventions, appears capable of activating the gradual correction that proceeds in parallel with the loosening of the inflation grip. There would be, then, a collaboration, natural but obliged, between the economic activity cycle and inflation profile, what is meaning that with rising inflation - due to the system instability the cyclical sequence speeds, while is increasing depth and duration of recessions. With the extension of recessions, the virtual wealth created by instability is destroyed, like in the recent speculative boom that has infected all the continents. Leaving the natural model free to operate, the creative destruction will end with the return of stability within the system that announces the resumption of development, without economic cycle, and with inflation under control. 


\section{References}

Bernanke, B. S. (2000). Essays on the great depression. New Jersey: Princeton University Press Princeton.

Cossiga, G. A. (2015a). The instability of economic systems and speculative market. The case of China. Scholedge International Journal of Management \& Development, $2,9$.

Cossiga, G. A. (2015b). Unstable economy: Reflections on the effects and consequences in the event of deflation (The case of Italy). International Journal of Economy, Management and Social Sciences, 4(10), 457-468.

Easterly, W., \& Bruno, M. (1995). Inflation crises and long-run growth. Journal of Monetary Economics, 41(1).

Friedman, M. (1968). The role of monetary policy. American Economic Review, 1.

Friedman, M. (2007). Milton friedman on economics: Selected papers. The University of Chicago Press.

Lucas, R. E. (1996). Nobel lecture: Monetary neutrality. Journal of Political Economy,104(4), 661-682.

Krugman, P. (1999). The return of depression on economics and the crisis of 2008. New York: Norton, W. W. \& Company, Inc.

Krugman, P. (2012). End this depression now. York: Norton, W. W. \& Company, Inc.

Krugman, P. (1998). Japan trap. May 1998.

Phelps, E. (1968). Money-Wage dynamics and labor-market equilibrium. Journal of Political Economy.

Phillips, W. (1958). The relation between unemployment and the rate of change of money wage rates in the United Kingdom, 1861-1957. Economica.

Reinhart, C. M., \& Rogoff, K. S. (2009). This time is different. Princeton and Oxford: Princeton University Press.

Reinhart, C. M., \& Savastano, M. A. (2002). Some lessons from modern hyperinflation. Washington International Monetary Fund Unpublished.

Roubini, N., \& Mihm, S. (2010). Crisis economics: A crash course in the future of finance. New York: The penguin press.

Samuelson, P. A., \& Solow, R. M. (1960). Analytical aspects of anti-inflation policy. The American Review, 50(2).

Schumpeter, J. (1947). Capitalism, socialism, and democracy. New York: Harper \& Brothers.

Stockman, A. C. (1998). Introduction to economics. Fort Worth, TX, U.S.A.: The Dryded Press.

OECD Statistics. Retrieved from http://www.oecd-ilibrary.org/ 


\section{Appendix A}

The supply curve is placed like foundation of a microeconomic market for final goods. In this market, the supply function of a manufacturer can be represented as follows:

$$
\mathrm{y}_{\mathrm{i}}=\mathrm{y}_{\mathrm{ni}}+\mathrm{a}\left(\mathrm{p}_{\mathrm{i}}-\mathrm{p}^{\mathrm{e}}\right)+\mathrm{u}_{\mathrm{i}}, \mathrm{a}>0
$$

$\mathrm{y}_{\mathrm{i}}$ is the current production of good $\mathrm{i}, \mathrm{y}_{\mathrm{ni}}$ is representing its natural or potential level, the prices $\mathrm{P}_{\mathrm{i}}$ and $\mathrm{P}^{\mathrm{e}}$ are the expectation of the i producer about the general price level. All manufacturers are in a stochastic environment, so before any change in the price of the goods produced by our manufacturer, he cannot know if there is a general movement of prices in all markets or a change of price just within his market. With this uncertainty, the manufacturer increases the current supply going over the natural level, because of lack of full information, as he is believing that the relative price of his products has increased when compared with the general level of prices, which are in fact unknown and therefore unexpected. The probability that the manufacturer is giving to this hypothesis, is measured by the positive coefficient $\alpha$.

Therefore, at the aggregate level, the function becomes:

$$
y_{t}=y_{n}+a\left(p_{t}-p_{t}^{e}\right)+u_{t}, a>0
$$

where $\mathrm{y}_{\mathrm{n}}$ represents the natural level of income, $\mathrm{u}_{\mathrm{t}}$ in fact is expressing the direct influence of any supply shock on the production. According to this hypothesis, changes in the supply of goods would be generated by a confusion between absolute and relative sizes or even by the inability of each producer to distinguish, in a stochastic environment, changes in demand generally attributable to a change within all markets or only inside their own market.

In the specific environment, characterized by the formation and growth of a speculative bubble, as in the mid-2000, we may assume that this anomalous information is strangely attenuated. This attenuation may depend on the speculative process in place, which is generating an irrational optimism about the economy performance. A sort of collective madness, dangerously invalidating the attention to risk, in a context of ample liquidity and easy credit. In other words, the distorted information from the virtual optimism generated by the "bubble", induces in the prospects a general expectation for growth, and on a transitional basis, reduces the capability to forecast errors:

$$
\varepsilon_{\mathrm{t}}=\mathrm{p}_{\mathrm{t}}-\mathrm{p}_{\mathrm{t}}^{\mathrm{e}}=-\frac{\mathrm{u}_{\mathrm{t}}}{\mathrm{b}} \sim 0
$$

In these specific conditions, it can be assumed that the $\varepsilon_{t}$ alteration induces a loss of effectiveness of the supply function, even with the concomitant effect of $\mathrm{u}_{\mathrm{t}}$ for the fictitious attenuation of shock on the supply side. It could be suggested a correction to function (1), by inserting a new addend represented by the factor "monetary interest", $\mathrm{v}_{\mathrm{t}}$, which expresses the influence of monetary policy on the process of economy development, in its role of safeguarding stability. In other words, we can admit that with the bubble dilation there is a reaction of monetary policy, to protect the unstable system. Thus, the supply function would take the form: $Y_{t}=\mathrm{Y}_{\mathrm{n}}+\alpha\left(\mathrm{P}_{\mathrm{t}}-\mathrm{P}_{\mathrm{t}}^{\mathrm{e}}\right)+\beta\left(\mathrm{v}_{\mathrm{t}}\right)+\mathrm{u}_{\mathrm{t}}$

The addition of addendum $\beta\left(\mathrm{v}_{\mathrm{t}}\right)$, indicating the influence of unexpected monetary policy (in a nutshell, the difference between the current interest rate minus the expected rate or previous year rate), would not have a real influence during periods of relative stability $\beta \sim 0$. Nevertheless, in periods of high volatility, the addition of $\beta\left(v_{t}\right)$ can adjust the supply function, so reducing the risk of an underestimation of $\varepsilon_{\mathrm{t}}$ Likewise, would be for $\alpha$, which is the relative probability $\mathrm{P}_{\mathrm{t}}^{\mathrm{e}}$ of hypothesis, where the coefficient $\beta$ represents the probability assigned to the hypothesis $\mathrm{v}_{\mathrm{t}}$.

Following this way, it is to be considered that the expression linking the prices evolution to the unemployment rate could be involved as well in a similar change. According to terms indicated by the research of M. Friedman, E. Phelps, and R. Lucas, the Phillips curve, revised according to rational expectations, takes the following expression:

$$
\mathrm{U}=\mathrm{U}_{\mathrm{n}}-\left(\Delta \mathrm{w} / \mathrm{w}-\pi_{\mathrm{e}}\right) / \mathrm{h}
$$


Since the wages inflation and prices inflation are closely related each other, $\pi$ can be substituting $\Delta \mathrm{w} / \mathrm{w}$ in the expression, so we will have:

$$
\mathrm{U}=\mathrm{U}_{\mathrm{n}}-\left(\pi-\pi_{\mathrm{e}}\right) / \mathrm{h}
$$

where $\left(\pi-\pi_{\mathrm{e}}\right)$ indicates the actual inflation minus the expected inflation.

In the case of an economy unstable for a long time, the error $\left(\pi-\pi_{\mathrm{e}}\right)$ may tend to contract for the creeping tendency towards deflation, which involves a system during the formation of a bubble followed by financial crisis. It could reach the spurious result $\mathrm{U} \sim \mathrm{U}_{\mathrm{n}}$. To overcome all problems, which could be arising from the probable underestimation of risk due to the "bubble" effect, we could follow the same method used in the case of the supply function. We can then propose the addition of an addendum $\beta\left(\mathrm{v}_{\mathrm{t}}\right)$ to the function (2), with the same features listed above, i.e., $\left(\mathrm{v}_{\mathrm{t}}\right)$ indicates the possibilities to influence the relationship exerted by monetary policy on its function of protecting the stability, and the coefficient $\beta$ represents the probability assigned to the hypothesis $\mathrm{v}_{\mathrm{t}}$.

The expression

$$
\mathrm{U}=\mathrm{U}_{\mathrm{n}}-\left(\pi-\pi_{\mathrm{e}}\right) / \mathrm{h}
$$

then may take the form:

$$
\mathrm{U}=\mathrm{U}_{\mathrm{n}}-\left(\pi-\pi_{\mathrm{e}}\right) / \mathrm{h}+\beta\left(\mathrm{v}_{\mathrm{t}}\right)
$$

The amendment, introduced to represent the augmented expectations on Phillips curve, could play an important meaning in the case of economies subject to high instability with extensive bubble. The addendum $\beta\left(\mathrm{v}_{\mathrm{t}}\right)$, indicating the influence of unexpected monetary policy, however, would not have an effective influence during the periods of relative stability $(\beta \sim 0)$. 